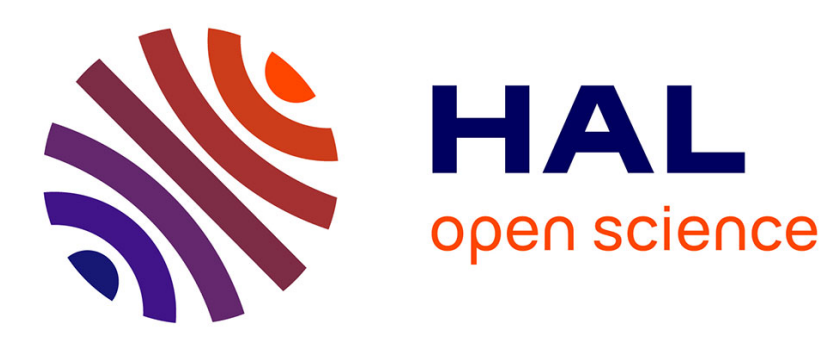

\title{
MAGNETISM AND EPR SPECTRA OF Mn +2Cu2+ FERRIMAGNETIC CHAINS
}

Olivier Guillou, D. Gatteschi, C. Zanchini, R. Sessoli, O. Kahn, M. Verdaguer, Y. Pei

\section{- To cite this version:}

Olivier Guillou, D. Gatteschi, C. Zanchini, R. Sessoli, O. Kahn, et al.. MAGNETISM AND EPR SPECTRA OF Mn +2Cu2+ FERRIMAGNETIC CHAINS. Journal de Physique Colloques, 1988, 49 (C8), pp.C8-857-C8-858. 10.1051/jphyscol:19888387 . jpa-00228573

\section{HAL Id: jpa-00228573 https://hal.science/jpa-00228573}

Submitted on 1 Jan 1988

HAL is a multi-disciplinary open access archive for the deposit and dissemination of scientific research documents, whether they are published or not. The documents may come from teaching and research institutions in France or abroad, or from public or private research centers.
L'archive ouverte pluridisciplinaire HAL, est destinée au dépôt et à la diffusion de documents scientifiques de niveau recherche, publiés ou non, émanant des établissements d'enseignement et de recherche français ou étrangers, des laboratoires publics ou privés. 


\title{
MAGNETISM AND EPR SPECTRA OF $\mathrm{Mn}^{+2} \mathrm{Cu}^{2+}$ FERRIMAGNETIC CHAINS
}

\author{
O. Guillou $\left({ }^{1}\right)$, D. Gatteschi $\left({ }^{1}\right)$, C. Zanchini $\left({ }^{1}\right)$, R. Sessoli $\left({ }^{1}\right)$, O. Kahn $\left({ }^{2}\right)$, M. Verdaguer $\left({ }^{2}\right)$ \\ and Y. Pei $\left({ }^{2}\right)$ \\ ( $\left.{ }^{1}\right)$ Department of Inorganic Chemistry, University of Florence, Florence, Italy \\ (2) Laboratoire de Spectrochimie des Eléments de Transition, UA 420, Université de Paris-Sud, 91405 Orsay, \\ France
}

Abstract. - Single crystal EPR spectra of the heterobimetallic chain compounds $\mathrm{MnCu}(\mathrm{pba})\left(\mathrm{H}_{2} \mathrm{O}\right)_{3} .2 \mathrm{H}_{2} \mathrm{O}(1)$ and $\mathrm{MnCu}(\mathrm{pbaOH})\left(\mathrm{H}_{2} \mathrm{O}\right)_{3}(2)$ where pba is 1,3-propylene-bis(oxamato) and $\mathrm{pbaOH}$ is 2-hydroxy-1,3-propylene-bis(oxamato) have been recorded in the 4.2-300 $\mathrm{K}$ temperature range. The angular dependence of the linewidths was interpreted in terms of dipolar interactions. The anisotropic shifts in the resonance fields observed at low temperature, due to short range order effects, are in agreement with the magnetic anisotropy measurements. EPR and magnetic data allow to propose the spin distribution in both compounds.

By reaction of monuclear copper (II) bricks with $\mathrm{Mn}^{2+}$ ions, we have synthesized the two bimetallic chain compounds $\mathrm{MnCu}(\mathrm{pba})\left(\mathrm{H}_{2} \mathrm{O}\right)_{3} .2 \mathrm{H}_{2} \mathrm{O}(\mathrm{I})$ and $\mathrm{MnCu}(\mathrm{pbaOH})\left(\mathrm{H}_{2} \mathrm{O}\right)_{3}(2)$ where $\mathrm{pba}$ is $1,3-$ propylene-bis(oxamato) and pbaOH is 2-hydroxy-1,3propylene- bis(oxamato) $[1,2]$. In both compounds, $\mathrm{Mn}^{2+}$ and $\mathrm{Cu}^{2+}$ nearest neighbor ions are bridged by oxamato ligands to form chains running along the $b$ direction of the orthorhombic lattice. The crystal packings are compared in figure 1. Owing to magnetic anisotropy measurements and single crystal EPR investigation, we have determined the spin distribution in both compounds.

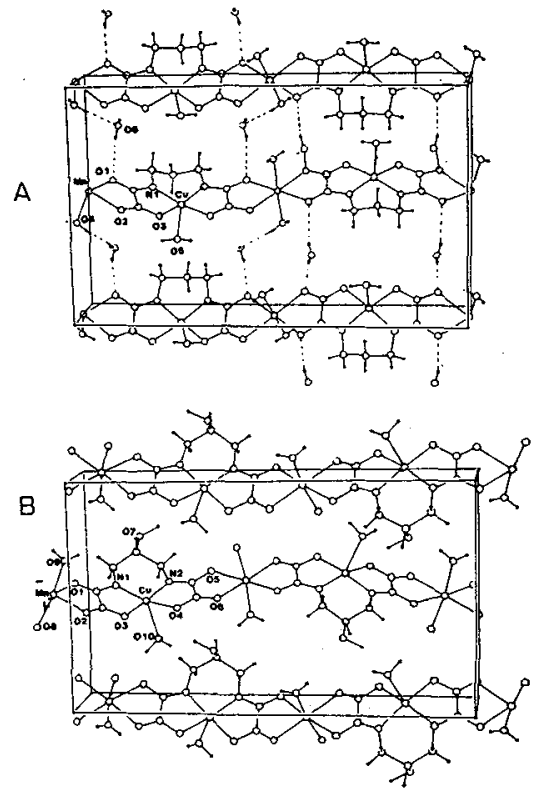

Fig. 1. - Perspective view of the content of the unit cell for (1) A and (2) B.

\section{Magnetic study}

The temperature dependences of the principal susceptibilities of (1) are shown in figure 2. Down to $2.6 \mathrm{~K}$, we have $\chi_{c}>\chi_{a}>\chi_{b}$. Below $2.6 \mathrm{~K}, \chi_{a}$ becomes larger than $\chi_{c}$ and presents a sharp maximum at $2.3 \mathrm{~K} . \chi_{a}$ and $\chi_{b}$ also present a maximum around $2.3 \mathrm{~K}$. Such a behavior reveals a 3-D antiferromagnetic ordering of the ferrimagnetic chains with $c$ as the easy axis and a weak canting of the spins in the $a$ direction. (2) orders ferromagnetically at $T_{\mathrm{c}}=4.6 \mathrm{~K}$. The principal magnetizations below $T_{\mathrm{c}}$ are such that $M_{c} \gg M_{b}>M_{a}$.

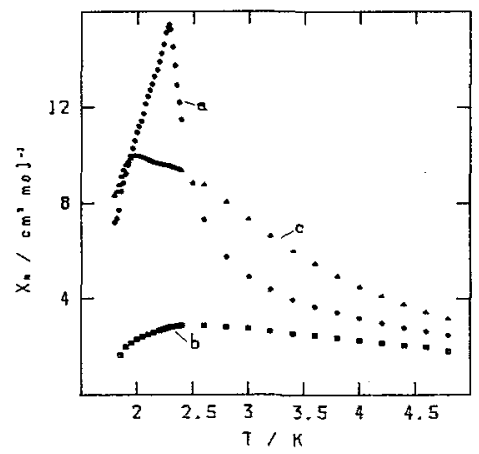

Fig. 2. - Temperature dependences of the principal susceptibilities for $\mathrm{MnCu}(\mathrm{pba})\left(\mathrm{H}_{2} \mathrm{O}\right)_{3} \cdot 2 \mathrm{H}_{2} \mathrm{O}(1)$.

\section{EPR study}

The room temperature single crystal EPR spectra for (1) have been recorded at both $X$ - and $Q$-band frequency, with the static magnetic field in the $b c, a c$ and $a b$ planes of the orthohombic lattice. The linewidth is largely angular dependent, as shown in figure 3 . The maxima of $\delta B_{\mathrm{pp}}$ are observed along the crystal axes, the order being $\delta B_{c}>\delta B_{b}>\delta B_{a}$. The minima on the other hand are observed almost exactly between the maxima at about $45^{\circ}$.

The temperature dependence of the spectra was followed along the three crystal axes. The most notable effect which is observed is the shift of the resonance fields at temperatures below $30 \mathrm{~K}$, as shown in figure 3 . The shift is upfield parallel to $b$, downfield parallel to $c$, and much less marked parallel to $a$. The spectra of (2) are rather similar to those of (1).

The spectra do not follow the 1-D ideal behavior. The broad lines observed at room temperature for both (1) and (2) are due to the fact that the strongest 


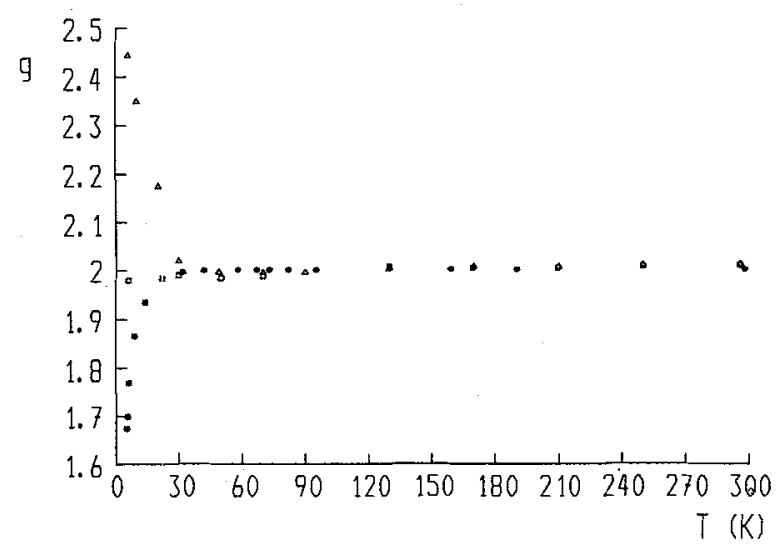

Fig. 3. - Temperatures dependences of the $g$ values for the $\delta M= \pm 1$ line for $(1)$ along $a(a), b(*)$ and $c(\Delta)$ axes.

dipolar interactions are between the chains. Considering that the spins are localized on the $\mathrm{Mn}^{2+}$ and $\mathrm{Cu}^{2+}$ ions respectively, we can estimate this broadening effect by evaluating the second moment $M_{2}$ relative to $\mathrm{Mn}-\mathrm{Mn}, \mathrm{Mn}-\mathrm{Cu}$ and $\mathrm{Cu}-\mathrm{Cu}$ interactions. $\mathrm{M}_{2}$ appears as a sum of two terms. The first term is the secular component, while the other two are the non-secular components. The former is expected to dominate in one-dimensional systems while all the terms should be used in three-dimensional systems.

We calculated first the secular dipolar second moment in the hypothesis that the Mn-Mn contributions are dominant. all the centers which are less than $15 \AA$ from the central metal ion were included in the calculation and, for (2), the sum was repeated for the two different manganese centers present in the cell. In order to innprove the fit, we added also $\mathrm{Cu}-\mathrm{Mn}$ contributions. The corrections were in the right direction, but small. The calculated values are put to a scale using the relation:

$$
\delta B_{\mathrm{pp}}=(4 / 3)^{2 / 3} M_{2}^{2 / 3} / J^{1 / 3}
$$

which is expected to be valid for one-dimensional systems. The value of the intrachain $\mathrm{Mn}-\mathrm{Cu}$ exchange parameter $J$ is that which was obtained by fitting the magnetic susceptibilities, i.e. $J=-24.8 \mathrm{~cm}^{-1}$. The calculated values are qualitatively in agreement with the experiment, as shown by the solid lines in figure 3 . Further, our results nicely confirm the importance of spin diffusion effects in these materials. Indeed, if the normal exchange conditions were attained, the angular dependence of the linewidths would be different, being determined by the full second moment rather than by the secular part only, and the widths of the lines would be much smaller since they would be governed by the relation: $\delta B_{p p}=M_{2} / J$. (Eq. (2)). Using (2), the maximum linewidths are calculated as $4.6 \mathrm{G}$ for (1) and $5.2 \mathrm{G}$ for (2), considering only the main $\mathrm{Mn}-\mathrm{Mn}$ interaction.

The anisotropic shifts in the resonance fields observed at low temperature are most likely due to short range order effects, i.e. to the spin correlation length which is increasing on decreasing temperature.

The resonance fields along the three principal axes can be expressed as: $B_{a}=\sqrt{\chi_{b} \chi_{c}} g B_{0} / \chi_{a} g_{a}$ (Eq. (3)) where $\chi_{a}, \chi_{b}$ and $\chi_{c}$ are the principal suceptibilities in the paramagnetic region; $g_{a}$ is the indicated principal $g$ value, $g=2.0032$, and $B_{0}$ is the resonance field of the free electron. The resonance fields for the other crystal directions follow from cyclic permutations.

The observed shifts compare well with the magnetic anisotropy data. The present EPR data at high temperature suggest that the main dipolar interaction must be parallel to $c$ and this orients the spins parallel to each other along this direction. Therefore, a spin distribution for (1) may be suggested, shown in figure 4. Such a spin structure agrees with the weak ferromagnetism observed for (1) along a because the antiferromagnetically coupled $\mathrm{Mn}^{2+}$ ions occupy magnetically not-equivalent sites. In this particular case, where the $\mathrm{Mn}^{2+}$ ion lies in a special position, only canting in the ac plane is possible, yielding weak ferromagnetism along $a$. The suggested structure seems to be the only one compatible with magnetic symmetry requirements. The difference between (1) and (2) lies mainly in the coupling in the planes orthogonal to $c:$ for $(1)$, this yields alternate planes with antiparallel spin alignment, while for (2), all the spins are parallel, leading to the ferromagnetic ordering observed at $4.6 \mathrm{~K}$.

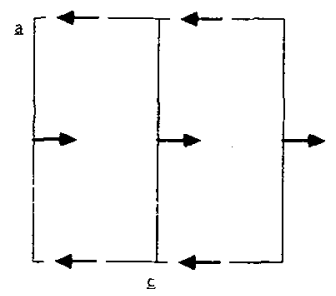

Fig. 4. - Schematic representation of the magnetic structure for (1) in the ac plane.

\section{Conclusion}

Thanks to their complementarity, the magnetic and EPR techniques have provided new insights on the mechanism of the 3-D magnetic ordering in the bimetallic chain compounds. In particular, the role of the dipolar interactions has been emphasized. These informations could allow us to design new molecularbased ferromagnets with, hopefully, higher $T_{\mathrm{c}}$.

[1] Kahn, O., Pei, Y., Verdaguer, M., Renard, J. P. and Sletten, J., J. Am. Chem. Soc. 110 (1988) 782.

[2] Pei, Y., Verdaguer, M., Kahn, O., Sletten, J. and Renard, J. P., Inorg. Chem. 26 (1987) 138.

[3] Gatteschi, D., Guillou, O., Zanchini, C., Sessoli, R., Kahn, O., Verdaguer, M. and Pei, Y., Inorg. Chem. (in press). 